\title{
Study of the colloidal stability and optical properties of sunscreen creams
}

Gustavo Pereira Saito ${ }^{1}$, Mariana Bizari¹, Marco Aurélio Cebim ${ }^{1 \oplus}$, Marcos Antonio Correa ${ }^{2 \oplus}$, Miguel Jafelicci Junior ${ }^{1 \oplus}$, Marian Rosaly Davolos ${ }^{1+(\text { CD }}$

1 São Paulo State University (Unesp), Institute of Chemistry, 55 Prof. Francisco Degni St, Araraquara, São Paulo, Brazil

2 São Paulo State University (Unesp), Faculty of Pharmaceutical Sciences, Km 1 Araraquara-Jaú Hw, Araraquara, São Paulo, Brazil

+ Corresponding author: Marian Rosaly Davolos, phone: +55 16 3301-9634, email address: marian.davolos@unesp.br

\section{ARTICLE INFO}

Article history:

Received: September 06, 2018

Accepted: January 29, 2019

Published: April 25, 2019

\author{
Keywords: \\ 1. viscosity \\ 2. colloidal stability \\ 3. thixotropic fluid \\ 4. optical absorption \\ 5. UV protection
}

ABSTRACT: Sunscreen formulations containing inorganic/organic filters or mixture of them were synthesized by oil/water dispersion. The viscosity measurements show that sunscreen formulations are timedependent non-newtonian fluids. In the CIELab color diagram, the white and/or beige colors presented by formulations do not compromise the aesthetics of the cosmetic product. UV-VIS absorption spectra show that sunscreen creams have high UV shielding ability, mainly the formulations containing inorganic and organic filters mixtures, which provide in vitro SPF and critical wavelength values recommended for UV protection.

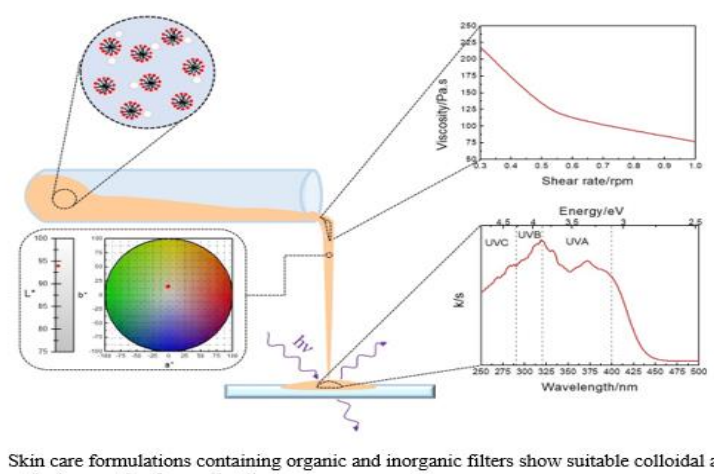

Skin care formulations containing organic and inorganic filters show suitable colloidal and optical properties for application as sunscreens.

\section{Introduction}

The excessive sun exposure causes cellular damage and immune system function modifications ${ }^{1,2}$. These damaging biological effects are caused by ultraviolet radiation (UV), which is responsible for the photochemical reactions in the human organism. UV radiation may be subdivided into following regions: UVC (100-290 nm), UVB $(290-320 \mathrm{~nm})$ and UVA $(320-400 \mathrm{~nm})^{3}$. However, the solar UV radiation which reaches the earth's surface is commonly composed by a combination of UVB and UVA radiation ${ }^{4}$. UVB radiation, although restricted to penetration of the upper layers of the skin, causes sunburns and direct DNA damage via pyrimidine dimer formation ${ }^{5}$. While the UVA radiation penetrates deeper into the skin causing photoaging, irregular pigmentation, immune system depression and gene modifications due mainly to the generation of reactive oxygen species by photosensitized oxidation ${ }^{6}$. Therefore, the sunscreen use to minimize the human health risks induced by UVB and UVA radiation exposure is very relevant ${ }^{7}$.

Sunscreens are skin care products whose main function is to protect the human skin from solar UV radiation $^{8}$. Analyzing from physical-chemical point of view, sunscreens are colloidal systems containing emulsions and/or particle dispersions. Generally, these colloidal systems are constituted by hydrophilic (e.g. water), hydrophobic (e.g. emollients) and amphiphilic (e.g. surfactants) 
compounds; therefore, sunscreens have suitable water-soluble and liposoluble properties to form films over the skin surface. Moreover, these properties provide sensory characteristics to sunscreens, which stimulate their use as skin cosmetics due to the facility of the cream removal with water and the skin hydration ${ }^{9}$.

Sunscreen application over human skin and the formation of the sunscreen film depend on their rheological properties, especially the colloidal stability. In this perspective, viscosity is an important property to evaluate the colloidal stability of sunscreens ${ }^{10}$, since it is directly associated to the surface interactions between sunscreen ingredients.

Inorganic and organic filters are sunscreen active ingredients ${ }^{11}$, i.e., the compounds responsible to the UV photoprotection of the human skin. Among inorganic and organic commercial filters, zinc oxide, 1-(4methoxyphenyl)-3-(4-tertbutylphenyl)propane-

1,3-dione and hexyl 2-(4-diethylamino-2hydroxybenzoyl)-benzoate have been widely used as broad spectrum filters in sunscreens due to their high UV shielding ability ${ }^{6}$.

Therefore, sunscreens must exhibit optical and rheological properties that allow photo-protective film formation on the human skin. In this perspective, the understanding of the intermolecular interactions between sunscreen ingredients, especially organic and inorganic filters, is very important for the development of stable and broad-spectrum sunscreens. In addition, the nature, amount and mixture of the filters directly influence optical and rheological properties of sunscreens due to the modification and/or formation of the new intermolecular interactions between their ingredients.

In the literature, several scientific publications show rheological and optical properties of sunscreen creams containing different and/or mixtures of sunscreen active ingredients ${ }^{10,12-18}$. However, the understanding of possible surface interactions between sunscreen constituents that influence the colloidal stability, mechanical and optical properties of sunscreen creams require more detailed studies. Thus, this work aims to investigate the colloidal stability and mechanical properties of sunscreen formulations containing different and/or mixture of organic and inorganic filters using the viscosity measurements as parameter to evaluate the surface interactions between sunscreen ingredients. Moreover, the optical properties of the sunscreen formulations were analyzed by UV-VIS spectrophotometric measurements to investigate sunscreen active ingredients interactions and potential UV shielding capacity of the sunscreen creams.

\section{Materials and methods}

\subsection{Sunscreen formulations}

Dipropan-2-yl hexanedioate (Dhaymers), 2,3dihydroxypropyl octadecanoate (Via Farma), mixture of hexadecan-1-ol and octadecan-1-ol (Cetostearyl alcohol, Via Farma), mixture of hexadecan-1-ol, octadecan-1-ol and oxirane (Cosmowax ${ }^{\circledR} \quad \mathrm{J}, \quad$ Croda), (1-decanoyloxy-3octanoyloxypropan-2-yl) dodecanoate (Via Farma), propane-1,2-diol (Qhemis), methyl 4hydroxybenzoate (Synth), propyl 4hydroxybenzoate (Synth), 2,2',2",2"'-(1,2Ethanediyldinitrilo)tetraacetic acid (Qhemis), 1-(4methoxyphenyl)-3-(4-tertbutylphenyl)propane1,3-dione (Eusolex ${ }^{\circledR}$ 9020, Merck) and hexyl 2-(4diethylamino-2-hydroxybenzoyl)-benzoate (Uvinul $^{\circledR}$ A Plus, BASF) and zinc oxide $(\mathrm{ZnO}$, Sigma-Aldrich) were used without further purification. The quantities of sunscreen active ingredients used meet the standards established by the Brazilian Health Surveillance Agency ${ }^{19}$. The molecular structures of sunscreen ingredients are shown in the Fig. 1 and Fig. 2.

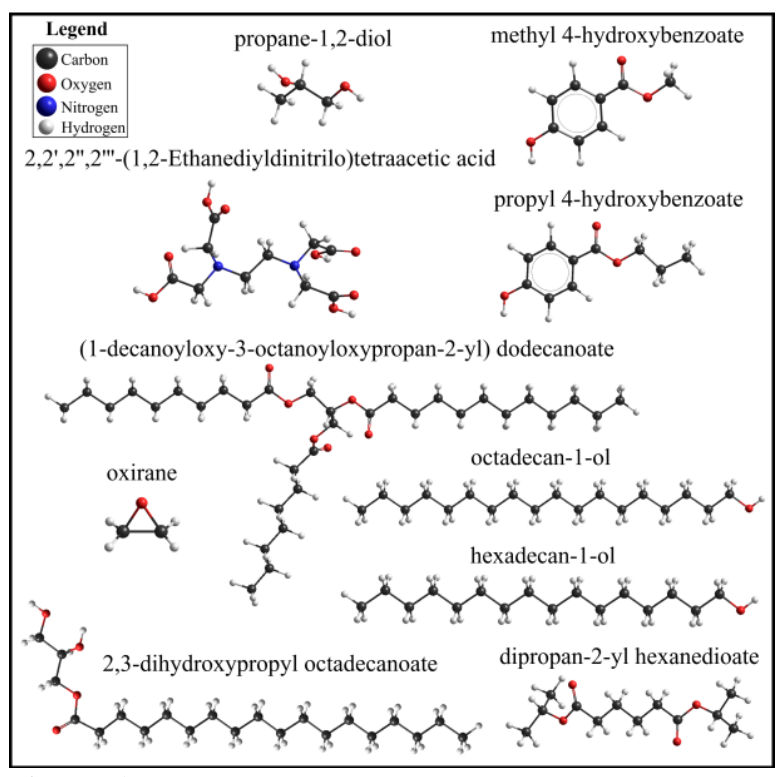

Figure 1. Molecular structures of sunscreen ingredients described in the Table 1. 


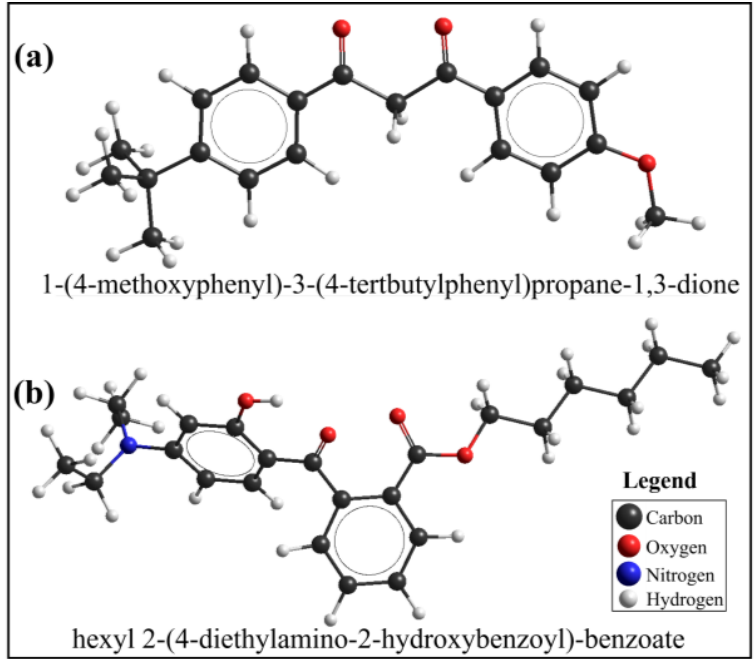

Figure 2. (a) Eusolex ${ }^{\circledR} 9020$ and (b) Uvinul ${ }^{\circledR}$ A Plus molecular structures.
The sunscreen formulations were obtained by dispersion of the oil phase constituents (Table 1) under aqueous phase constituents (Table 1). The oil phase and aqueous phase ingredients were weighed and subjected to heating at $75{ }^{\circ} \mathrm{C}$ for 5 minutes.

Then, the oil phase was poured under the aqueous phase and the sunscreen cream obtained was kept under stirring for $1 \mathrm{~h}$. The mass percentage of the sunscreen ingredients and the respective sunscreen formulations are shown in Tables 1 and 2.

Table 1. Mass percentage of the ingredients of the sunscreen formulations containing different UV filters.

\begin{tabular}{lccccc}
\hline \multirow{2}{*}{ Ingredients } & \multirow{2}{*}{ Phase } & \multicolumn{3}{c}{ Sunscreen formulations/\% } \\
\cline { 3 - 6 } & & $\mathbf{B}$ & $\mathbf{E}$ & $\mathbf{U}$ & $\mathbf{Z}$ \\
\hline Cetostearyl alcohol & Oil & 2.00 & 2.00 & 2.00 & 2.00 \\
2,3-dihydroxypropyl octadecanoate & Oil & 2.00 & 2.00 & 2.00 & 2.00 \\
Cosmowax $^{\circledR}$ J. & Oil & 8.00 & 8.00 & 8.00 & 8.00 \\
Dipropan-2-yl hexanedioate $^{\text {1-decanoyloxy-3-octanoyloxypropan-2-yl)dodecanoate }}$ & Oil & 1.50 & 1.50 & 1.50 & 1.50 \\
Uvinul $^{\circledR}$ A Plus & Oil & 1.50 & 1.50 & 1.50 & 1.50 \\
Eusolex $^{\circledR}$ 9020 & Oil & - & - & 10.00 & - \\
ZnO & Oil & - & 5.00 & - & - \\
Propane-1,2-diol & Oil & - & - & - & 25.00 \\
Methyl 4-hydroxybenzoate & Aqueous & 4.00 & 4.00 & 4.00 & 4.00 \\
Propyl 4-hydroxybenzoate & Aqueous & 0.18 & 0.18 & 0.18 & 0.18 \\
2,2',2",2"'-(1,2-Ethanediyldinitrilo)tetraacetic acid & Aqueous & 0.02 & 0.02 & 0.02 & 0.02 \\
Water & Aqueous & 0.05 & 0.05 & 0.05 & 0.05 \\
\hline
\end{tabular}

Table 2. Mass percentage of the ingredients of the sunscreen formulations containing Uvinul ${ }^{\circledR}$ A Plus, $\mathrm{ZnO}$ or mixtures of them.

\begin{tabular}{|c|c|c|c|c|c|c|c|c|c|}
\hline \multirow{2}{*}{ Ingredients } & \multicolumn{9}{|c|}{ Sunscreen formulations $/ \%$} \\
\hline & U1 & U2 & U3 & Z1 & $\mathbf{Z 2}$ & $\mathbf{Z 3}$ & $\mathbf{U Z}$ & UZ1 & UZ2 \\
\hline $\begin{array}{l}\text { Oil phase } \\
\text { ingredients }\end{array}$ & 15.00 & 15.00 & 15.00 & 15.00 & 15.00 & 15.00 & 15.00 & 15.00 & 15.00 \\
\hline Uvinul $^{\circledR}$ A Plus & 5.00 & 2.50 & 1.00 & - & - & - & 10.00 & 5.00 & 1.00 \\
\hline $\mathrm{ZnO}$ & - & - & - & 10.00 & 5.00 & 1.00 & 1.00 & 1.00 & 1.00 \\
\hline $\begin{array}{l}\text { Aqueous phase } \\
\text { ingredients }\end{array}$ & 4.25 & 4.25 & 4.25 & 4.25 & 4.25 & 4.25 & 4.25 & 4.25 & 4.25 \\
\hline Water & 75.75 & 78.25 & 79.75 & 70.75 & 75.75 & 79.75 & 69.75 & 74.75 & 78.75 \\
\hline
\end{tabular}

\subsection{Characterization techniques}

The viscosity curves of sunscreen formulations were collected on a Brookfield rotational viscometer, model LVDV-E, equipped with a temperature control system $\left(28-60^{\circ} \mathrm{C}\right.$ temperature range) using a cylindrical sample holder and No. 63 spindle $(11 \mathrm{~mm}$ spindle diameter $)$. Diffuse reflectance spectra of sunscreen formulations were recorded on a Cary spectrophotometer, model 500 UV-VIS-NIR, equipped with diffuse reflectance accessory. Color index was obtained in a Konica Minolta spectrophotometer, model CM-2500d, equipped with $\mathrm{d} / 8^{\circ}$ integrating sphere (CIELab 
color space). The sun protection factor (SPF) of sunscreen formulations was obtained from diffuse reflectance relative measurements using the in vitro SPF assessment ${ }^{20}$, which is defined by

$\mathrm{SPF}=\frac{\int_{200}^{400} \mathrm{E}(\lambda) \mathrm{S}(\lambda) \mathrm{d} \lambda}{\int_{290}^{400} \mathrm{E}(\lambda) \mathrm{S}(\lambda) \mathrm{T}(\lambda) \mathrm{d} \lambda}$

In the Eq. 1, the $T(\lambda)$ corresponds to the optical diffuse transmittance of sunscreen creams as a function of wavelength $(\lambda)$ and the wavelength integration limits refers to the combined UVB and UVA wavelength range. $\mathrm{E}(\lambda)$ is the erythema action spectrum and $S(\lambda)$ is the spectral irradiance of terrestrial sunlight under defined conditions by International Organization for Standardization ${ }^{21}$. The UVA protection of sunscreen creams was analyzed using the critical wavelength $\left(\lambda_{c}\right)$, i.e., the wavelength value where the area under UV spectrum from $290 \mathrm{~nm}$ to a specific wavelength correspond to $90 \%$ of the integral of the absorption spectrum in the $290-400 \mathrm{~nm}$ region ${ }^{22}$.
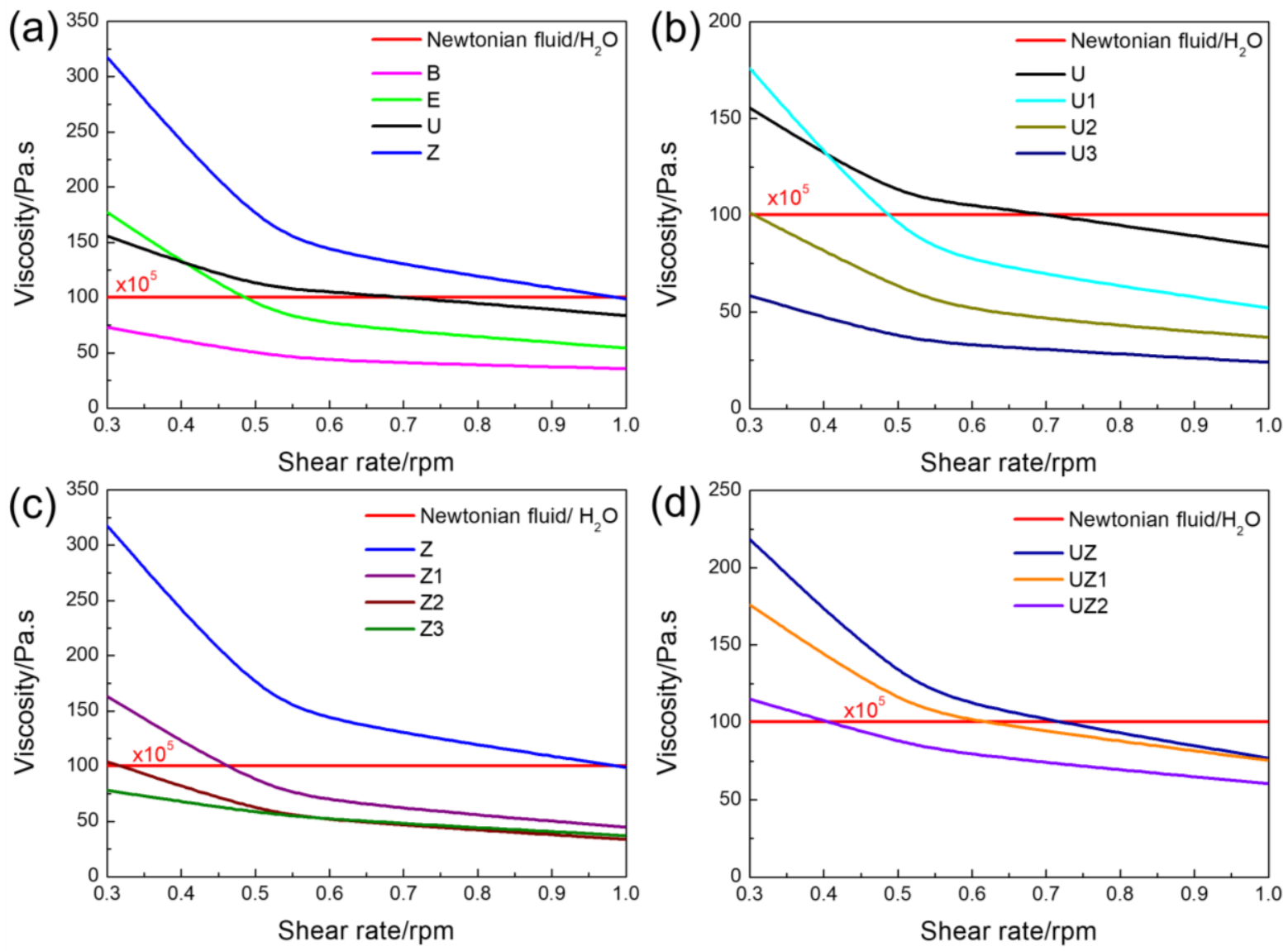

Figure 3. Viscosity-shear rate curves of sunscreen formulations containing different mass percentages of (a) sunscreen active ingredients, (b) Uvinul ${ }^{\circledR}$ A Plus, (c) $\mathrm{ZnO}$ and (d) mixture of Uvinul ${ }^{\circledR}$ A Plus and $\mathrm{ZnO}$, as shown in Tables 1 and 2. 
The inorganic or organic filter presence and/or their increase in the cosmetic formulations cause the viscosity increase; it is associated with interfacial structuring in sunscreen formulations that contributes significantly to the colloidal stability. Thus, the sunscreen active ingredients used and their amount present in formulations provide modifications in the colloidal stability due to the conformation, rearrangement and degree of interaction of these chemical compounds with the ingredients of the colloidal systems, especially with the surfactants ${ }^{25,26}$. In sunscreen formulations, Cetostearyl alcohol, Cosmowax ${ }^{\circledR} \mathrm{J}$ and 2,3dihydroxypropyl octadecenoate compounds (Fig. 1) are the emulsifying agents or surfactants of these colloidal systems.

The sunscreen formulations containing $\mathrm{ZnO}$ have higher viscosity values when compared to the others. This fact indicates possible surface interactions of the zinc oxide with sunscreen ingredients and/or the formation of zinc oxide agglomerates. According to the literature, surface interactions between zinc oxide particles and ions or molecules depend on the surface charge of these particles, which is correlated with the $\mathrm{pH}$ of the particle dispersion ${ }^{27}$. Moreover, particle agglomeration in colloidal systems is associated to the ionic strength, the nature of the chemical environment and the morphological properties of the $\mathrm{ZnO}$ particles ${ }^{28}$.

The viscosity-time curves under constant shear rate (Fig. 4) show that the viscosity of sunscreen formulations decreases as the measurement time increases. This rheological behavior exhibited indicates the formulations are thixotropic fluids, i.e., time-dependent non-newtonian fluids ${ }^{29}$. Therefore, the creams have essential rheological characteristics for application as sunscreens because thixotropic fluids when subjected to an external force present viscosity decrease providing their application in the human skin. Moreover, the viscosity returns the initial state after the force removal allowing the formation of a photoprotective film on the skin surface.

Comparing the viscosity-time curves of $\mathrm{B}$ and $\mathrm{E}$ formulations to others, it is observed an initially viscosity increase in the $0-60 \mathrm{~s}$ time interval. This viscosity increase is associated to the interfacial region changes due to the deformation and reorganization of dispersed molecules in the interface $^{24,29}$, which provide specific viscoelastic properties for these colloidal systems.
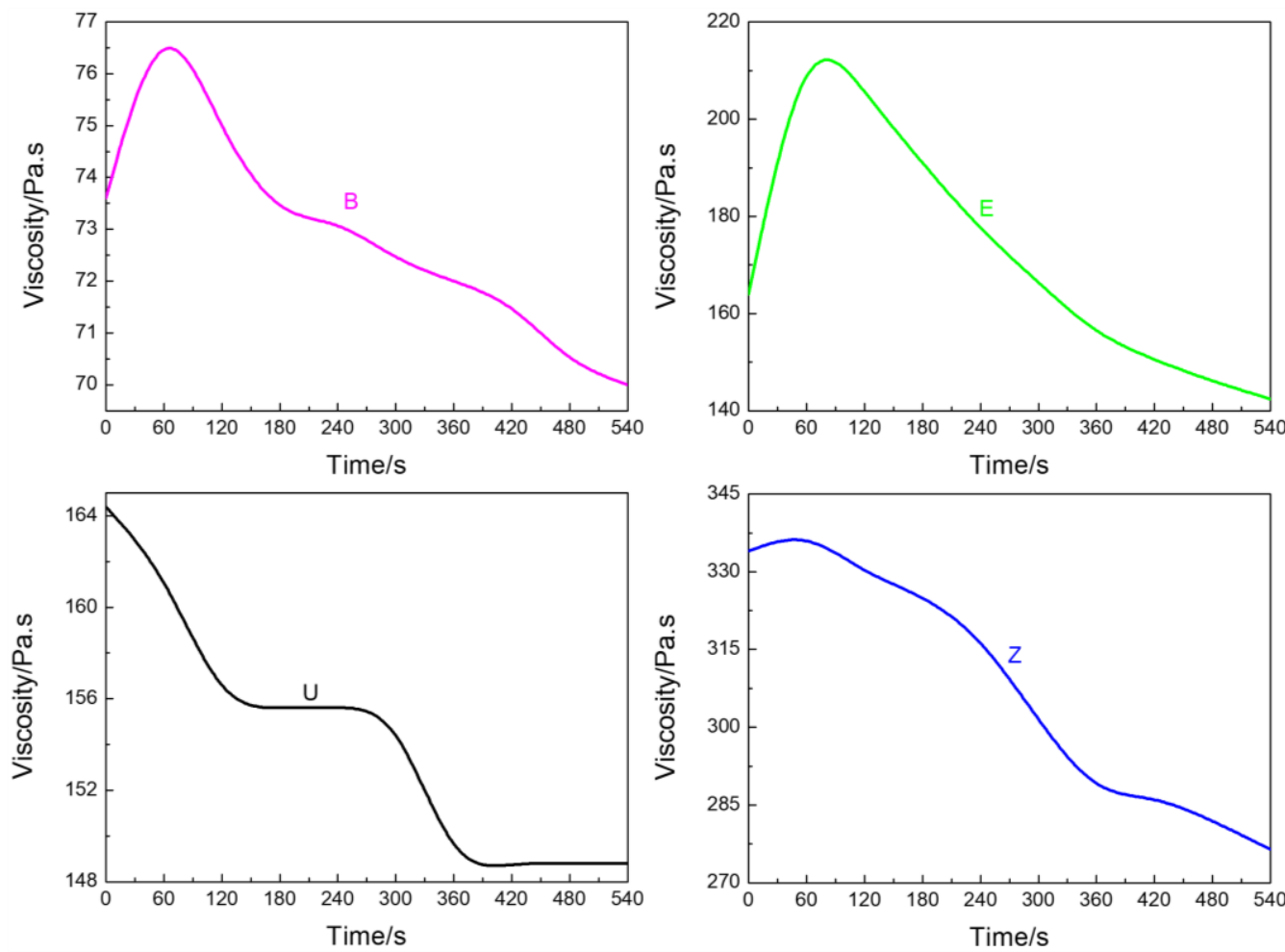

Figure 4. Viscosity-times curves of B, E, U and Z sunscreen formulations indicated in Tables 1 and 2. 
The colloidal stability of sunscreen formulations depends on the interfacial structuring, which is maintained by surface interactions between sunscreen ingredients. Thus, the temperature variation changes the interfacial region promoting loss and/or gain of the colloidal stability; consequently, the sunscreen viscosities are modified. The Fig. 5 shows the temperature effect on the viscosity of the sunscreen creams.

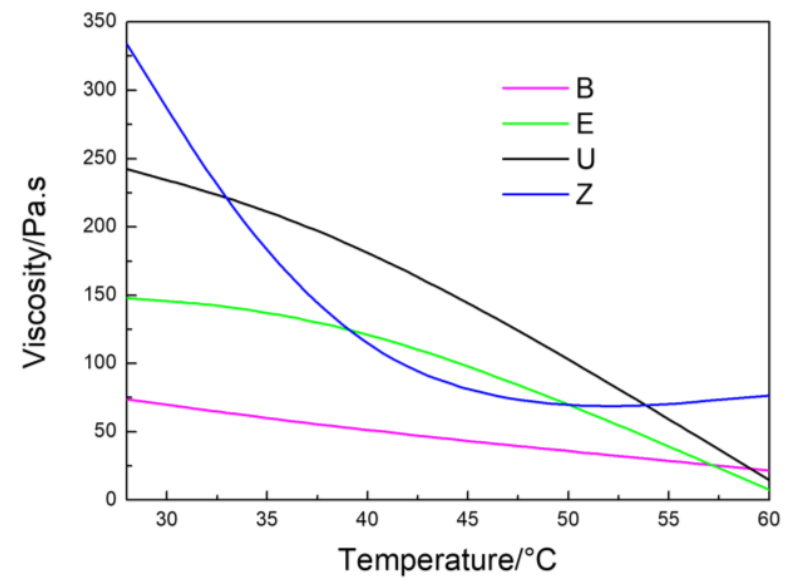

Figure 5. Viscosity-temperature curves of B, E, U and $\mathrm{Z}$ sunscreen formulations indicated in Tables 1 and 2.

In the temperature-viscosity curves, it is observed the viscosity decrease of the sunscreen formulations with the temperature increase. This viscosity decrease is attributed to the break of intermolecular interactions in the interfacial region, which provides the loss of the colloidal stability. In addition, the sunscreen formulation containing $\mathrm{ZnO}$ exhibits different rheological behavior compared to the other formulations in the $40-60{ }^{\circ} \mathrm{C}$ temperature range. This rheological behavior can be associated to the agglomeration and/or dispersion of the $\mathrm{ZnO}$ particles in the formulation.

The temperature-dependence of sunscreen viscosity can be correlated with the Arrhenius equation $^{30}$ according to Eq. 2 :

$\eta=\eta_{0} e^{\left(\frac{E_{a}}{R T}\right)}$

where $\eta$ is the viscosity of formulations, $\eta_{0}$ is the empirical constant and $E_{\mathrm{a}}$ is the flow activation energy. The flow activation energy $\left(E_{\mathrm{a}}\right)$ is the potential energy barrier that interfacial molecules need to overcome in order to the fluid flow to occur; consequently, the $E_{\mathrm{a}}$ values show the degree of the temperature-dependence of viscosity ${ }^{31}$. Thus, temperature-dependence of viscosity is small for viscous fluids that have low $E_{\mathrm{a}}$ values.

In this perspective, flow activation energy can be a parameter used to evaluate the temperature influence on the colloidal stability of sunscreen creams containing different UV filters. The flow activation energy values of the sunscreen formulations are shown in Table 3. Independent of sunscreen active ingredient used in the colloidal system, the experimental $E_{\mathrm{a}}$ values show that sunscreen creams have high temperaturedependence of their viscosity; therefore, the colloidal stability of them is directly affected by the temperature restricting their application as stable cosmetic cream in a temperature range. In addition, the flow active energy values presented by the sunscreen formulation containing $\mathrm{ZnO}$ show a nonnewtonian rheological behavior in the investigated temperature range. Consequently, the difference of $E_{\mathrm{a}}$ values indicates that surface relaxations between zinc oxide and sunscreen ingredients medium depend on the temperature, giving rise to different interfacial structuring of the colloidal dispersion ${ }^{32}$.

Table 3. Flow activation energy $\left(E_{\mathrm{a}}\right)$ values of $\mathrm{B}$, $\mathrm{E}, \mathrm{U}$ and $\mathrm{Z}$ formulations.

\begin{tabular}{cc}
\hline Sunscreen formulation & $\boldsymbol{E}_{\mathbf{a}} / \mathbf{~ k J ~ m o l}^{-\mathbf{1}}$ \\
\hline B & 32.15 \\
E & 81.09 \\
U & 76.42 \\
$Z$ & $121.19 \% 17.00^{\mathrm{b}}$ \\
\hline${ }^{\mathrm{a}} E_{\mathrm{a}}$ value obtained in $28-40^{\circ} \mathrm{C}$ temperature range. \\
${ }^{\mathrm{b}} E_{\mathrm{a}}$ value obtained in $40-60^{\circ} \mathrm{C}$ temperature range.
\end{tabular}

\subsection{Optical properties}

The diffuse reflectance spectra (Fig. 6) show that each sunscreen formulation has a specific visible light scattering $(400-800 \mathrm{~nm})$, which is associated to micellar structures formed and their size in the cosmetic cream; therefore, organic or inorganic filter used have significant contribution to the formation of the micellar structures. Moreover, the visible light scattering in the sunscreen formulations containing inorganic filter is also related to the $\mathrm{ZnO}$ particles depending on their size ${ }^{8}$. 

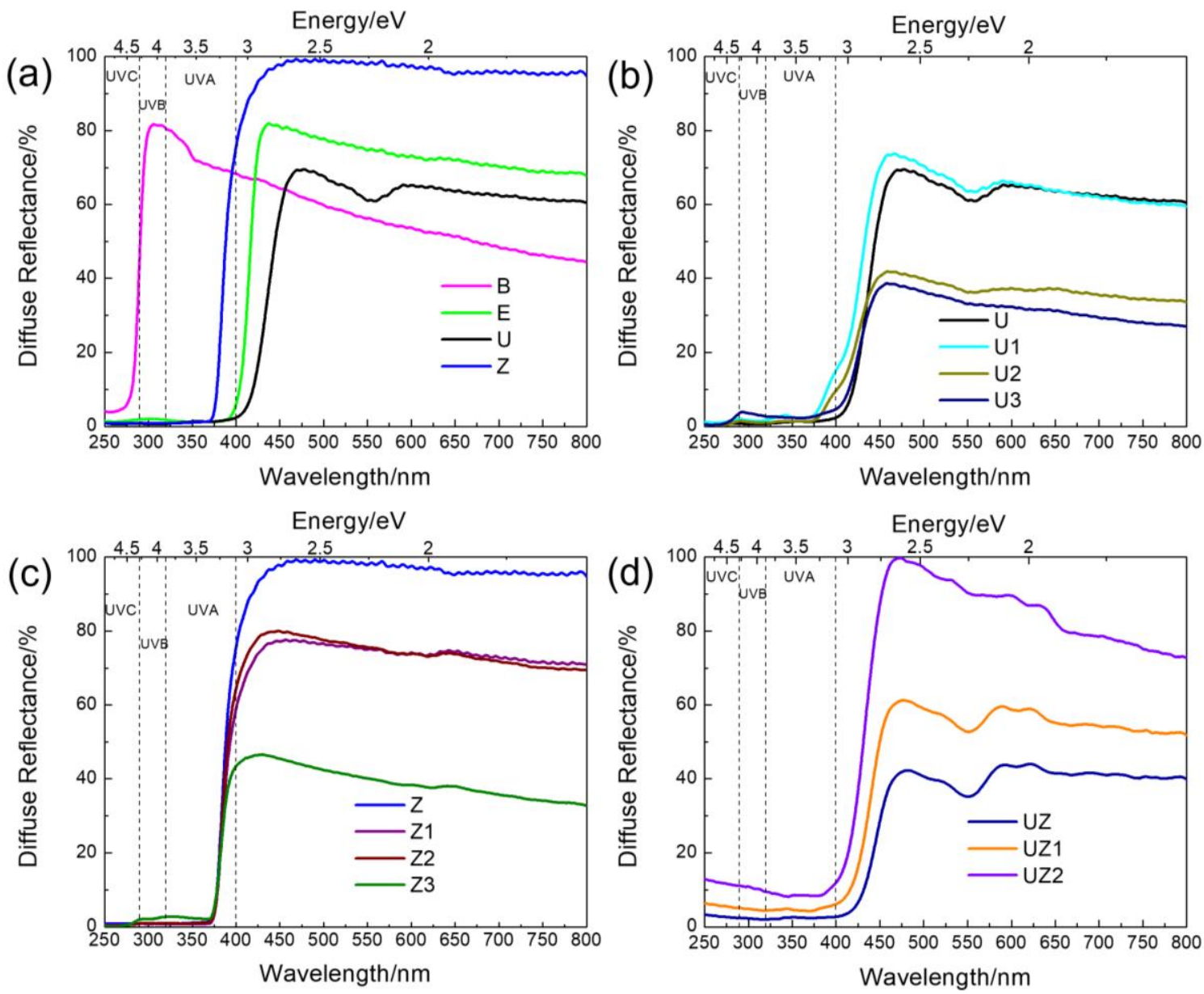

Figure 6. Diffuse reflectance spectra of the sunscreen formulations containing several mass percentages of (a) different UV filters, (b) Uvinul ${ }^{\circledR}$ A Plus, (c) $\mathrm{ZnO}$ and (d) mixture of Uvinul ${ }^{\circledR}$ A Plus and $\mathrm{ZnO}$, as shown in Tables 1 and 2.

The UV-VIS absorption spectra of sunscreen formulations obtained by Kubelka-Munk equation $^{33}$ are shown in Fig. 7. In the absorption spectrum of the B cream (Fig. 7a), it is observed a broad and low intensity absorption band in the 250$290 \mathrm{~nm}$ region attributed to the $\pi \rightarrow \pi^{*}$ and/or $\eta \rightarrow \pi^{*}$ transitions ${ }^{34}$ due to aromatic rings and/or carbonyl groups present in the molecular structures of sunscreen ingredients (Fig. 1). The absorption spectra of sunscreen formulations containing organic and inorganic filters or mixture of them (Fig. 7) show a typical band of sunscreen ingredients and characteristic absorption bands of the UV filters.

In the sunscreen creams containing organic filters (Fig. 7a and Fig. 7b), the broad absorption bands with maximum values at 312 and $370 \mathrm{~nm}$ are attributed to $\pi \rightarrow \pi^{*}$ and/or $\eta \rightarrow \pi^{*}$ transitions. These electronic transitions assigned are characteristics of the beta-diketones ${ }^{35}$ and benzophenone-derived compounds $^{36}$, such as the Eusolex ${ }^{\circledR}$ and Uvinul ${ }^{\circledR}$ A Plus filters used in the sunscreen formulations. In addition, the mass percentages variation of the Uvinul ${ }^{\circledR}$ A Plus causes absorption edge shifts and intensity modifications of these absorption bands probably due to the different micellar structures obtained, which provide energy changes in the frontier molecular orbitals of the organic filter.

The sunscreen creams containing inorganic filter (Fig. 7c) present a broad and high intensity absorption band in the 290-380 $\mathrm{nm}$ region attributed to $\mathrm{VB} \rightarrow \mathrm{CB}$ transitions from the $\mathrm{ZnO}$ semiconductor $^{8}$. In the sunscreen formulations containing mixtures of Uvinul $^{\circledR}$ A Plus and $\mathrm{ZnO}$ (Fig. 7d), it is observed the enlargement, overlapping and displacement of the specific absorption bands of these UV filters when compared to the other formulations. Probably, this optical behavior is correlated to the interactions between Uvinul $^{\circledR}$ A Plus and $\mathrm{ZnO}$ surface, which cause modifications in the energy levels of the organic filter and/or the formation of new molecular orbitals that give rise to different electronic transitions. 

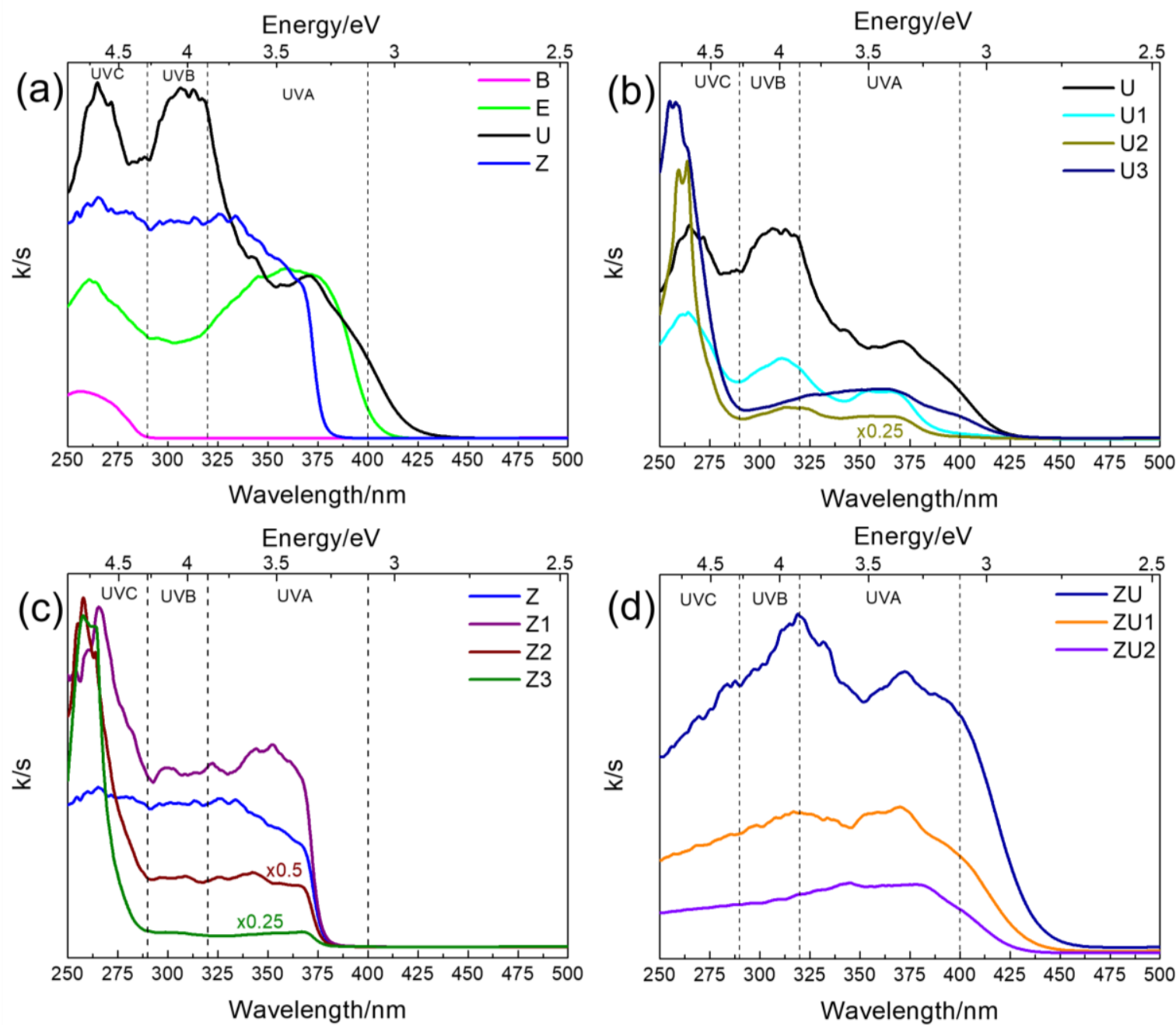

Figure 7. Absorption spectra of the sunscreen formulations containing several mass percentages of (a) different UV filters, (b) Uvinul ${ }^{\circledR}$ A Plus, (c) ZnO and (d) mixture of Uvinul ${ }^{\circledR}$ A Plus and ZnO, as shown in Tables 1 and 2.

The CIELab color diagram (Fig. 8) shows that sunscreen formulations are white or beige depending on the UV filter present in their composition; consequently, their colors do not compromise the desired aesthetics appearance for the cosmetic products.

The UV shielding performance of the skin care products was analyzed by in vitro sunscreen measurement methods ${ }^{37}$, which are based on UVVIS spectrophotometric measurements. Comparing the sun protection factor (SPF) and critical wavelength values (Fig. 9) of sunscreen creams with a commercial sunscreen product (SPFlabelled equal to 10) and also comparing them to sunscreens described in the BASF sunscreen simulator $^{38}$, it is verified the in vitro method used shows coherent and satisfactory results allowing the evaluation of UV shielding capacity of sunscreen creams.
According to the literature ${ }^{39}$, sunscreens that have SPF values $\leq 15$ prevent skin damages caused by UVB radiation, moreover, critical wavelength values greater than $370 \mathrm{~nm}$ show that sunscreens have potential for UVA protection. Therefore, all sunscreen formulations obtained present UVB protection (Fig. 9), however, only formulations containing organic filter have potential UVA shielding capacity. In addition, UZ and UZ1 creams present better UV shielding ability when compared to the others due to synergistic effect from the mixture of $\mathrm{ZnO}$ and Uvinul ${ }^{\circledR} \mathrm{A}$ Plus filters in specific mass percentages. This synergistic effect is probably associated to surface interactions between inorganic and organic filters, which are observed in the absorption spectra of these sunscreen creams (Fig. 7d). 

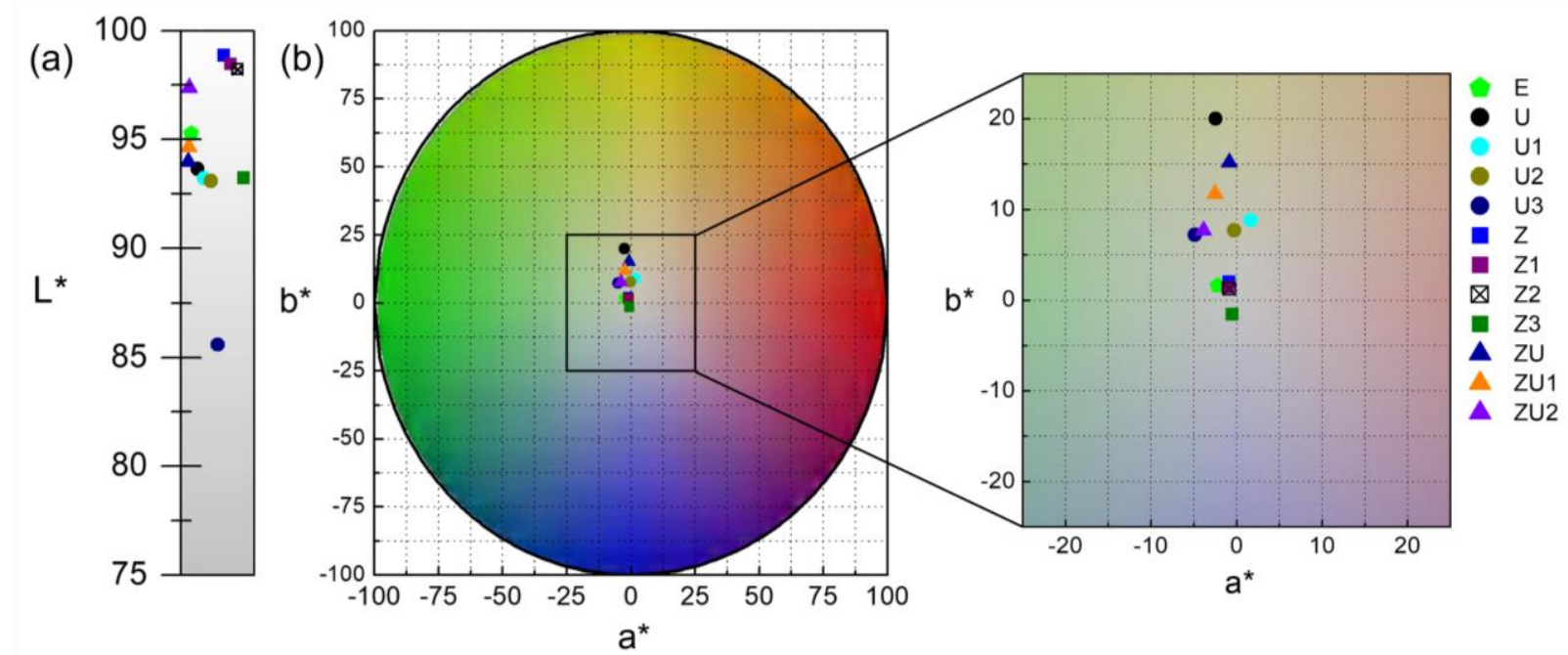

Figure 8. (a) Brightness scale and (b) color scale corresponding to the CIELab color diagram of sunscreen formulations described in Tables 1 and 2.

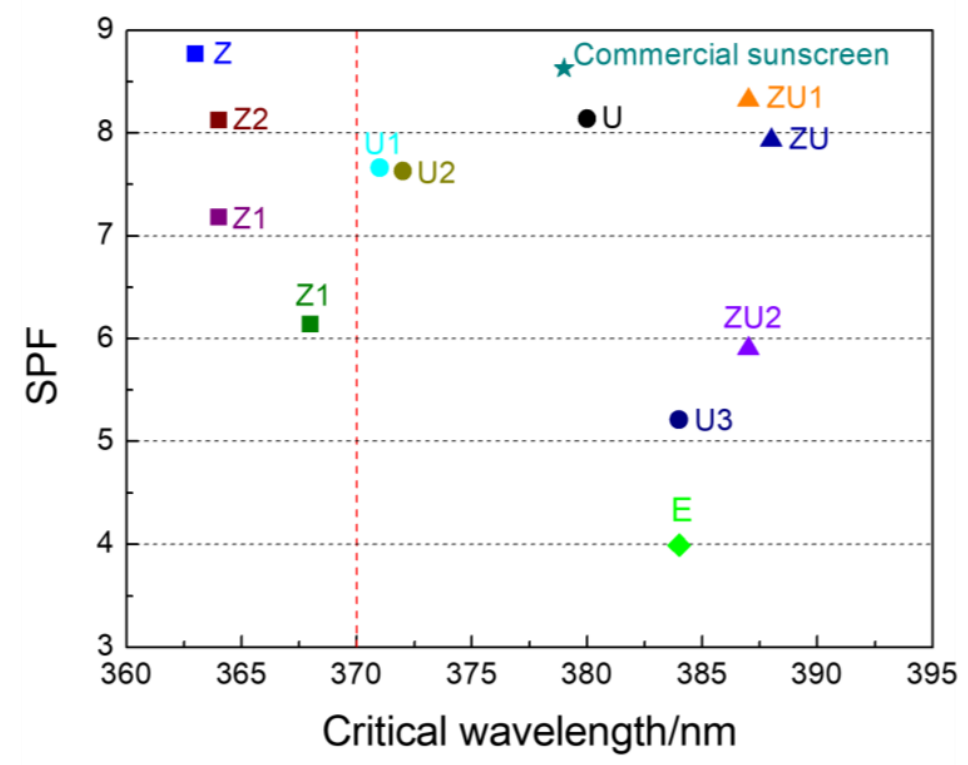

Figure 9. SPF and critical wavelengths of sunscreen formulations described in the Tables 1 and 2.

\section{Conclusions}

The sunscreen formulations obtained are timedependent non-newtonian colloidal systems classified as thixotropic fluids. The colloidal stability of these thixotropic fluids depends on both the temperature and the sunscreen active ingredients presence in their composition. It can be remarked that the flow activation energy $\left(E_{\mathrm{a}}\right)$ obtained by the viscosity measurements is an essential parameter to evaluate the temperature influence on the colloidal stability of sunscreen formulations. The UV-VIS absorption/scattering properties of the sunscreen creams are also correlated to the inorganic/organic filters or mixture of them, which provide SPF and critical wavelength values recommended for UV protection. It is important to emphasize that the synergistic effects from the inorganic and organic filters mixtures result in a better UV shielding performance of the sunscreen formulations as observed for UZ and UZ1 samples containing 10.00 or $5.00 \mathrm{wt}^{2}$ Uvinul $^{\circledR}$ A Plus, respectively, and $1.00 \mathrm{wt} \%$ zinc oxide. Furthermore, white and beige colors presented by creams do not compromise the desired aesthetics appearance for the skin care products. Therefore, sunscreen formulations investigated in this work have 
colloidal stability and suitable optical properties for application as sunscreens.

\section{Acknowledgments}

This work was developed with institutional infrastructure financed by FAPESP, CNPq and CAPES (Brazilian Agencies). G.P.S thanks CNPq for the granted scholarship.

\section{References}

[1] Baker, L. A., Marchetti, B., Karsili, T. N. V., Stavros, V. G., Ashfold, M. N. R., Photoprotection: extending lessons learned from studying natural sunscreens to the design of artificial sunscreen constituents, Chem. Soc. Rev. 46 (2017) 3770-3791. https://doi.org/10.1039/C7CS00102A.

[2] Cole, C., Appa Y., Ou-Yang, H., A broad spectrum high-SPF photostable sunscreen with a high UVA-PF can protect against cellular damage at high UV exposure doses, Photodermatol. Photoimmunol. Photomed. 30 (2014) 212-219. https://doi.org/10.1111/phpp.12124.

[3] Velasco, M. V. R., Sarruf, F. D., Salgado-Santos, I. M. N., Haroutiounian-Filho, C. A., Kaneki, T. M., Baby, A. R., Broad spectrum bioactive sunscreens, Int. J. $\begin{array}{llll}\text { Pharm. } & 363 & \text { (2008) 50-57. }\end{array}$ https://doi.org/10.1016/j.ijpharm.2008.06.031.

[4] Fourtanier, A., Moyal, D., Seite, S., UVA filters in sun-protection products: regulatory and biological aspects, Photochem. Photobiol. Sci. 11 (2012) 81-89. https://doi.org/10.1039/C1PP05152K.

[5] Sambandan, D. R., Ratner, D., Sunscreens: An overview and update, J. Am. Acad. Dermatol. 64 (2011) 748-758. https://doi.org/10.1016/j.jaad.2010.01.005.

[6] Kockler, J., Oelgemöller, M., Robertson, S., Glass, B. D., Photostability of sunscreens, J. Photochem. Photobiol., C. $\quad 13 \quad$ (2012) 91-110. https://doi.org/10.1016/j.jphotochemrev.2011.12.001.

[7] Sohn, M., Herzog, B., Osterwalder, U., Imanidis, G., Calculation of the sun protection factor of sunscreens with different vehicles using measured film thickness distribution-Comparison with the SPF in vitro, J. Photochem. Photobiol., B. 159 (2016) 74-81. https://doi.org/10.1016/j.jphotobiol.2016.02.038.

[8] Flor, J., Davolos, M. R., Correa, M. A., Sunscreens, Quim. Nova. $30 \quad$ (2007) 153-158. https://doi.org/10.1590/S0100-40422007000100027.
[9] Cross, S. E., Jiang, R., Benson, H. A. E., Roberts, M. S., Can Increasing the Viscosity of Formulations be used to Reduce the Human Skin Penetration of the Sunscreen Oxybenzone?, J. Invest. Dermatol. 117 (2001) 147-150. https://doi.org/10.1046/j.1523-1747.2001.01398.x.

[10] Calixto, L. S., Maia Campos, P. M. B. G., PhysicalMechanical characterization of cosmetic formulations and correlation between instrumental measurements and sensorial properties, Int. J. Cosmet. Sci. 39 (2017) 527534. https://doi.org/10.1111/ics.12406.

[11] Hernández, J. M. G., Escalante, A., Vázquez, R. N. M., Delgado, E., González, F. J., Toríz, G., Use of Agave tequilana-lignin and zinc oxide nanoparticles for skin photoprotection, J. Photochem. Photobiol. B. 163 (2016) $156-161$. https://doi.org/10.1016/j.jphotobiol.2016.08.027.

[12] Gaspar, L. R., Maia Campos, P. M. B. G., Rheological behavior and the SPF of sunscreens, Int. J. Pharm. $250 \quad$ (2003) 35-44. https://doi.org/10.1016/S0378-5173(02)00462-3.

[13] Santoro, M. I. R. M., Oliveira, D. A. G. C. E., Kedor-Hackmann, E. R. M., Singh, A. K., The effect of packaging materials on the stability of sunscreen emulsions, Int. J. Pharm. 297 (2005) 197-203. https://doi.org/10.1016/j.ijpharm.2005.03.021.

[14] Nasu, A., Otsubo, Y., Rheology and UV protection properties of suspensions of fine titanium dioxides in a silicone oil, J. Colloid Interface Sci. 296 (2006) 558564. https://doi.org/10.1016/j.jcis.2005.09.036.

[15] Rigo, L. A., Rascovetzki, R. H., Beck, R. C. R., Sunscreen formulations containing rice bran or soybean oil: rheological properties, spreadability and in vitro sun protection factor, Lat. Am. J. Pharm. 30 (2) (2011) 24652. http://hdl.handle.net/10915/8130.

[16] Sierra, A. F., Ramírez, M. L. G., Campmanya, A. C. C., Martínez, A. R., Naveros, B. C., In vivo and in vitro evaluation of the use of a newly developed melatonin loaded emulsion combined with UV filters as a protective agent against skin irradiation, J. Dermatol. $\begin{array}{llll}\text { Sci. } & 69 & \text { (2013) 202-214. }\end{array}$ https://doi.org/10.1016/j.jdermsci.2012.10.013.

[17] Amnuaikit, T., Boonme, P., Formulation and characterization of sunscreen creams with synergistic efficacy on SPF by combination of UV filters, J. Appl. Pharm. Sci. 3 (2013) $1-5$. https://doi.org/10.7324/JAPS.2013.3801.

[18] Seixas, V. C., Serra, O. A., Stability of Sunscreens Containing $\mathrm{CePO}_{4}$ : Proposal for a New Inorganic UV 
Filter, Molecules $19 \quad$ (2014) 9907-9925. https://doi.org/10.3390/molecules19079907.

[19] Technical Regulation MERCOSUR on ultraviolet filter list permitted for toiletries, cosmetics and perfumes. Brazilian Health Surveillance Agency. Resolution RDC No. 69. Ministry of Health (Brazil): National Press; 2016.

[20] Binks, B. P., Fletcher, P. D. I., Johnson, A. J., Marinopoulos, I., Crowther, J., Thompson, M. A., How the sun protection factor (SPF) of sunscreen films change during solar irradiation, J. Photochem. Photobiol. A. 333 (2017) 186-199. https://doi.org/10.1016/j.jphotochem.2016.10.027.

[21] ISO 24443:2012, Determination of sunscreen UVA photoprotection in vitro, International Organization for Standardization, 2012.

[22] Diffey, B. L., A method for broad spectrum classification of sunscreens, Int. J. Cosmet. Sci. 16 (1994) 47-52. https://doi.org/10.1111/j.14672494.1994.tb00082.x.

[23] Vand, V., Viscosity of solutions and suspensions. I. Theory, J. Phys. Colloid. Chem. 52 (1948) 277-299. https://pubs.acs.org/doi/pdf/10.1021/j150458a001.

[24] Malkin, A.Y., Non-Newtonian viscosity in steadystate shear flows, J. Nonnewton. Fluid. Mech. 192 (2013) 48-65. https://doi.org/10.1016/j.jnnfm.2012.09.015.

[25] Tambe, D. E., Sharma, M. M., The effect of colloidal particles on fluid-fluid interfacial properties and emulsion stability, Adv. Colloid Interface Sci. 52 (1994) 1-63. https://doi.org/10.1016/00018686(94)80039-1.

[26] Tambe, D., Paulis, J., Sharma, M. M., Factors Controlling the Stability of Colloid-Stabilized Emulsions: IV. Evaluating the Effectiveness of Demulsifiers, J. Colloid Interface Sci. 171 (1995) 463469. https://doi.org/10.1006/jcis.1995.1203.

[27] Degen, A., Kosec, M., Effect of pH and impurities on the surface charge of zinc oxide in aqueous solution, J. Eur. Ceram. Soc. 20 (2000) 667-673. https://doi.org/10.1016/S0955-2219(99)00203-4.

[28] Bian, S. W., Mudunkotuwa, I. A., Rupasinghe, T., Grassian, V. H., Aggregation and Dissolution of $4 \mathrm{~nm}$ ZnO Nanoparticles in Aqueous Environments: Influence of pH, Ionic Strength, Size, and Adsorption of Humic Acid, Lagmuir. $27 \quad$ (2011) 6059-6068. https://doi.org/10.1021/la200570n.
[29] Lee, C. H., Moturi, V., Lee, Y., Thixotropic property in pharmaceutical formulations, J. Control. $\begin{array}{llll}\text { Release } & 136 & \text { (2009) 88-98. }\end{array}$ https://doi.org/10.1016/j.jconrel.2009.02.013.

[30] Juszczak, L., Fortuna, T., Rheology of selected Polish honeys, J. Food. Eng. 75 (2006) 43-49. https://doi.org/10.1016/j.jfoodeng.2005.03.049.

[31] Huang, B., Liang, S., Qu, X., The rheology of metal injection molding, J. Mater. Process. Technol. 137 (2003) 132-137. https://doi.org/10.1016/S09240136(02)01100-7.

[32] Morrison, F. A., Experimental Data, In: Understanding rheology, first ed., Oxford University Press, New York, 2001, Ch. 6.

[33] Loyalka, S. K., Riggs, C. A., Inverse problem in diffuse reflectance spectroscopy: Accuracy of the Kubelka-Munk equations, Appl. Spectrosc. 49 (1995) 1107-1110.

[34] Pavia, D. L., Lampman, G. M., Kriz, G. S., Vyvyan, J. A., Ultraviolet spectroscopy, In: Introduction to spectroscopy, fourth ed., Cengage Learning, Belmont, 2009, Ch. 7.

[35] Wetz, F., Routaboul, C., Lavabre, D., Garrigues, J. C., Lattes, I. R., Pernep, I., Denis, A., Photochemical Behavior of a New Long-chain UV Absorber Derived from 4-tert-Butyl-4'-Methoxydibenzoylmethane, J. Photochem. Photobiol. 80 (2004) 316-321. https://doi.org/10.1111/j.1751-1097.2004.tb00089.x.

[36] Porter, G., Suppan, P., Primary photochemical processes in aromatic molecules. Part 12.-Excited states of benzophenone derivatives, Trans. Faraday Soc. 61 (1965)

https://doi.org/10.1039/TF9656101664.

1664-1673.

[37] Stanfield, J., Osterwalder, U., Herzog, B., In vitro measurements of sunscreen protection, Photochem. $\begin{array}{lllll}\text { Photobiol. } & \text { Sci. } & 9 & \text { (2010) 489-494. }\end{array}$ https://doi.org/10.1039/B9PP00181F.

[38] BASF Sunscreen Simulator, Prediction of SPF and UVA-Metrics.

https://www.sunscreensimulator.basf.com/Sunscreen_S imulator/Input_show.action, 2018.

[39] Wang, S. Q., Lim, H. W., Current status of the sunscreen regulation in the United States: 2011 Food and Drug Administration's final rule on labeling and effectiveness testing, J. Am. Acad. Dermatol. 65 (2011) 863-869. https://doi.org/10.1016/j.jaad.2011.07.025. 